\begin{tabular}{|l|}
\hline Presented at the: \\
4th World Summit on the Knowledge Society \\
21-23 September 2011 \\
Mykonos, Greece
\end{tabular}

\title{
Upward influence tactics in virtual work settings
}

\author{
Sebastián Steizel ${ }^{1}$, and Eva Rimbau-Gilabert ${ }^{2}$, \\ ${ }^{1}$ Universidad de San Andrés, Vito Dumas 284 \\ (B1644BID) Buenos Aires, Argentina \\ ssteizel@udesa.edu.ar
}

${ }^{2}$ Internet Interdisciplinary Institute (IN3) \& Business and Economy Studies. Universitat Oberta de Catalunya, Av. Tibidabo 39-43, 08035 Barcelona, Spain erimbau@uoc.edu

\begin{abstract}
The globalization of work within organizations has generated a greater need for all type of workers to exert interpersonal influence through technology-mediated communication tools. This paper contributes to the analysis of interpersonal relations in virtual environments from a specific perspective: the choice of upward influence tactics. We propose that virtual work settings may impact the upward influence tactic selected, as well as the communication medium used to enact it. In particular, we study whether the types of upward influence strategies found in presence environments, are relevant in a virtual work context. This research also analyzes the link between communication media and influence tactics used. Preliminary results suggest that there is an influence tactic that is specific of virtual work relations, which may be called intermediation and consists of finding an intermediary that is well connected with the target and can help in defining the best approach by the agent.
\end{abstract}

Keywords: Influence tactics, upwards influence, virtual communication, virtual relationship.

\section{Introduction}

The globalization of work within organizations is an unavoidable reality in today's business world. We are increasingly dealing with virtual work arrangements in which employees of the same company or different companies must collaborate through technology-mediated communication tools. These new forms of work are associated with the development of new organizational structures that take the form of interconnected, small organizational units, which are marked by lower hierarchical control, and more horizontal relations. In such context, there is greater need for rethinking interpersonal relations in general, and interpersonal influence in particular ([1], [2]). 
Although interpersonal influence is a key element in this new organizational reality, it has mostly been studied in traditional or presence environments. The present work contributes to the analysis of interpersonal relations in virtual environments from a specific perspective: the choice of upward influence strategies. Within influence relationships, probably those exercised by employees towards their employers or managers express the purest form of influence. In the absence of any hierarchical authority and prerogatives, employees must often exercise influence over their managers to do their jobs, and get resources to achieve results. In addition, such influence is nowadays increasingly exerted through more horizontal relations and the use of electronic media, which probably impact the chosen influence tactics and their effects.

Therefore, the research presented in this paper analyzes the influence tactics used by subordinates working in virtual environments, in pursuing to influence their supervisors. Specifically, we address the following questions: Are the types of upward influence tactics found in presence environments relevant in a virtual work context? Which is the impact of the communication medium on the choice of upward influence tactics? Preliminary results regarding the first question are presented.

\section{Theoretical background}

Research on influence tactics has covered both its antecedents and its consequences, but it has rarely mentioned virtual environment or media technology as variables to be taken into account (for a review see [3], [4]). Only a few studies have analyzed the phenomenon of influence tactics in virtual environments. Elron and Vigoda [5] for example, found that task focus, the centrality of the team, and the familiarity among members were factors that affected the use of influence tactics in virtual teams. Other authors have focused on the process of virtual influence, analyzing this phenomenon as a dynamic process in which the influence strategy is affected by the target perception and their reaction to the influence intent [2]. Dealing specifically with the impact of the communication media, Barry and Bateman [6] suggested that influence tactics and media usage, were influenced by the hierarchical position of the individuals and the direction of the intention of influence (upwards, downwards or horizontal). The work of Cho et al. [7] is the only one that has specifically focused on upward influence tactics. They found that personal preference in terms of influence tactics, and interpersonal relationship between agent and target, affected media choice. The present paper continues this stream of research but takes a different perspective, since it focuses on the impact of the media on the upward influence tactic choice.

The first question this paper addresses is whether the types of upward influence strategies found in presence environments, are relevant in a virtual work context. In a virtual work setting, new communication tools may foster or hinder the use of certain strategies, thus rendering the traditional classification of presence-based influence inapplicable. The logic behind this question is based on the assumptions developed by the Adaptive Structuration Theory (AST). AST provides a model that describes the interplay between advanced information technologies, social structures, and human 
interaction. DeSanctis and Poole explain that "advanced information technologies trigger adaptive structurational processes which, over time, can lead to changes in the rules and resources that organizations use in social interaction." ([8], pp:142-143). For this reason we expect that as employees assimilated the technologies available, their modes of relation will be affected, not only in altering the known forms of linkage, but also creating new emerging forms.

The classification developed by Kipnis et al. [9] is one of the more wide used to assess interpersonal influence. Kipnis and his associates developed a taxonomy of influence tactics which gathers together six tactics:

- Ingratiation: using a friendly or helpful behavior to get the other in a good mood.

- Exchange: offering an exchange of positive benefits or asking to make a concession or personal sacrifice.

- Rationality: use of logical persuasive arguments based on reason.

- Assertiveness: making repeated request or use pressure.

- Upward appeal: causing additional pressure to conform by invoking the influence of higher levels in the organization

- Coalition: using the assistance of others or noting their support to persuade the other to comply with the desired goal.

This scheme has been one the most used in research about influence tactics, and has been empirically and methodologically validated over the years (see [10], [11], [12], and [13]). Although the findings about frequency and use of influence tactics in presence environments are not always consistent, the data obtained from the main studies shows that the tactics that prevail in presence environments are rationality and ingratiation, followed by coalition ([9], [11]).

Even though this taxonomy is one of the most comprehensive, the virtual work context may provide opportunities to develop new forms of influence tactics or -at least- may change the relative weigh of each tactic as compares to presence settings. This proposed change is based on the following characteristics of the virtual environment:

- There is a lack of mutual knowledge among the members of the influence dyad, which impacts mutual understanding between them [14].

- Virtual communication offers less social cues, which also affects the information exchange process [15].

- Virtual teams tend to have more of a task-focus and less of a social-focus than traditional teams [16].

- Distance work involves a work between different national cultures, and this variable may impact on the influence choice ([5], [17], [18]).

These structural features of virtual media may impact relationship building and, thus, the upward influence process. As posed by Contractor and Eisenberg (in [19]), the communication structures and the organizational use given to the media shape each other in an emerging pattern of social interaction. Therefore, in interpersonal relations framed by virtual settings where the primary ways of communication are technology mediated, we expect to find new upward influence strategies or new characteristics in the findings about upward influence tactics in presence environments. 
The second question studies the link between the communication medium and the influence tactics used. We expect to find that people choose their upward influence tactics according to the technological resources they have available and according to the objectives they are pursuing. This proposition is based on the Media Synchronicity Theory (MST) ([20], [21]), which proposes that different media have different capabilities, and according those capabilities there are better combinations between media choice and the purposes the employee wants to achieve.

\section{Methodology}

The proposed methodology to address these issues combines the use of $<$ quantitative and qualitative strategies. We will obtain data from semi-structured interviews with employees of multinational companies who have their supervisors at a distance, asking them about their tactics to influence their supervisor. This step will provide information to confirm or change the influence tactics inventories that have been developed for presence settings.

A questionnaire addressed to a wider sample of multinational employees will be used to evaluate the frequency of the diverse influence tactics used in virtual environments, and their combination with different technologies. The instrument used to measure influence tactics is an adaptation of the model developed by Kipnis et al [9], and updated by Schriescheim and Hinkin [12], called the POIS (Profile of Organizational Influence Strategies).

\section{$4 \quad$ Preliminary findings}

Preliminary results from semi-structured interviews suggest that there is a particular set of upward tactics that emerge in a virtual environment. Most of the interviewees highlighted that a task-oriented relationship is built under this kind of work environment. They also underscored that the formal content of this communication interactions affects the way they influence their supervisors and the media they select for that purpose. Because of the lack of informal social interaction that could add data about each side's situation, there is not a common understanding of the context under which each member of the influence dyad is talking or listening (country context, physical context, target network, internal power distribution, local organization dynamics, etc.). This weak information about the supervisor's situation leads people to be careful in their intention to influence their supervisors. The tactics that are more frequently mentioned in the interviews are 1) rationality; 2) what we have dubbed intermediation; and 3) coalition. Whit rationality tactics, the subordinates' attempt to get things from their supervisors is mainly based on logical argumentation to support their requests. This is the more accepted way to approach the supervisor. The way interviewees use this tactic follows a two-step sequence: they firstly send an electronic mail to brief the supervisor about the request and, after some time, they resort to a call conference to reinforce the arguments and complete the influence intent. 
The second tactic emerged in the interviews, which we have called intermediationadds a new tactic to the aforementioned list by Kipnis et al. Many subordinates state that when they have difficult issues to discuss, and they don't know how their supervisor might react to their request, they look for someone that is close to their supervisor (physically or socially) and who could help them to transmit their intentions. This intermediary could be local colleagues of the agent, or local colleagues of the target. The main point is to find someone who is proximate to and trusted by the target, is able to understand the target's context, and can then suggest the best way to approach him/her. When the intermediary is at the same place than the agent, the face-to-face interaction is the selected media. When this person is at a distance they tend to prefer the telephone.

The third tactic used, especially when there is a team involved, is coalition. Before the influence intention, many subordinates try to build an agreement among their peers to present the request as a collective issue.

\section{References}

1. Fulk, J., DeSanctis, G. Electronic communication and changing organizational forms. Organization Science, 6(4), 337-349. (1995).

2. Barry, B., Fulmer, I. S. The medium and the message: The adaptive use of communication media in dyadic influence. Academy of Management Review, 29(2), 272-292. (2004)

3. Barbuto J., J., Moss, J. Dispositional Effects in Intra-Organizational Influence Tactics: A Meta-Analytic Review. Journal of Leadership \& Organizational Studies, 12(3), 30-52(2006).

4. Higgins, C. A., Judge, T. A., Ferris, G. R. Influence tactics and work outcomes: A meta-analysis. Journal of Organizational Behavior, 24: 89-106 (2003).

5. Elron, E., Vigoda-Gadot, E. Influence and political processes in cyberspace: The case of global virtual teams. International Journal of Cross Cultural Management : CCM, 6(3), 295. (2006).

6. Barry, B., Bateman, T. Perceptions of influence in managerial dyads - the role of hierarchy, media, and tactics. Human Relations, 45(6), 555-574 (1992)

7. Cho, N., Park, K., Su, C. Effects of the Upward Influence Strategies on the Communication Media Selection. Contemporary Management Research, 137-154, 4(2), (2008)

8. DeSanctis, G., Poole, M. S. Capturing the complexity in advanced technology use: Adaptive structuration theory. Organization Science, 5(2), 121-147 (1994)

9. Kipnis, S., Schmidt, S., Wilkinson, I. Intraorganizational influence tactics: exploration in getting one's way. Journal of Applied Psychology, 65(4), 440-452 (1980)

10. Schilit, W., Locke, E. A Study of Upward Influence in Organizations. Administrative Science Quarterly, 27(2), 304-316 (1982)

11. Yukl, G., Falbe, C. M. Influence tactics and objectives in upward, downward, and lateral influence attempts. Journal of Applied Psychology, 75(2), 132-140 (1990)

12. Schriesheim, C. A.; Hinkin, T. R. Influence tactics used by subordinates: A theoretical and empirical analysis and refinement of the Kipnis, Schmidt, and Wilkinson subscales. Journal of Applied Psychology, 75(3), 246-257 (1990) 
13. Farmer, S.M., Maslyn, J.M., Fedor, D.B., Goodman, J.S. Putting Upward Influence Strategies in Context. Journal of Organizational Behavior, 18, 17-42 (1997)

14. Cramton. C.D. The Mutual Knowledge Problem and Its Consequences for Dispersed Collaboration Organization Science, 12(3), 346-371 (2001)

15. Sproull, L., Kiesler, S. Reducing social context cues: electronic mail in organizational communication. Management Science, 32 (11), 1492-1512 (1986)

16. Chidambaram, L., Bostrom, R. Evolution of Group Performance Over Time: A Repeated Measures Study of GDSS Effects. Journal of Organizational Computing, 3(4), 443-469 (1993)

17. Hirokawa, R., Miyahara, A. A Comparison of Influence Strategies Utilized by Managers in American and Japanese Organizations. Communication Quarterly, 34(3), 250-265 (1986)

18. Yeh, Ryh-Song. Downward influence styles in cultural diversity settings. The International Journal of Human Resource Management, 6(3) (1995)

19. Fulk, J. Social construction of communication technology. Academy of Management Journal, 36(5), 921-950 (1993)

20. Maruping, L. M., Agarwal, R. Managing team interpersonal processes through technology: A task-technology fit perspective. Journal of Applied Psychology, 89(6), 975-990 (2004)

21. Dennis, A.; Fuller, R.; Valacich, J. Media, tasks, and communication processes: A theory of media synchronicity. MIS Quarterly, 32(3), 575-600 (2008) 